\title{
Methodology for assessing the efficiency of water jet pumps in auxiliary systems of irrigation pumping stations
}

\author{
Eduard $\mathrm{Kan}^{1 *}$, Muradulla Mukhammadiev ${ }^{2}$, Afanasiy $\mathrm{Li}^{1}$, and SHerali Aralov ${ }^{3}$ \\ ${ }^{1}$ Department of Usage of water energy and pumping stations, Tashkent Institute of Irrigation and \\ Agricultural Mechanization Engineers, 100000 Tashkent, Uzbekistan \\ ${ }^{2}$ Department of power, Tashkent State Technic University named after Islam Karimov, 100095 \\ Tashkent, Uzbekistan \\ ${ }^{3}$ Moscow State University of Civil Engineering, Yaroslavskoe shosse 26, Moskow, Russia
}

\begin{abstract}
The reliability and efficiency of irrigation pumping stations operation primarily depends on the well-coordinated operation of all systems. Drainage system should ensure that the building and territory of the pumping station are not flooded by drainage (filtration) water. At many pumping stations (especially those with long pressure lines), water jet pumps are installed as pumps for pumping out drainage water. The experience of operating such plants has revealed their undeniable advantages in comparison with conventional vane centrifugal pumps (type $\mathrm{K}$ and $\mathrm{D}$ ) - sufficient reliability in operation due to the simplicity of the design, the absence of rubbing parts in the installation, the possibility of pumping contaminated liquids and the possibility of their use in the absence of power supply. But with all this, water jet pumps are extremely low-efficiency. To justify the use of jet pumps, a methodology is needed that would allow for a comprehensive consideration of all the main factors that affect their reliability, ease of operation and energy efficiency in the drainage system. On the example of the pumping station "Kiziltepa-2", these factors were identified and the energy efficiency of water jet pumps was calculated. Various applications of jet pumps are considered, and their efficiency is evaluated.
\end{abstract}

\section{Introduction}

Water jet pumps are widely used in the oil and gas industry, energy, construction, transport and water management $[1,2,3,4,5]$. Recent trends are use water-jet pumps in drainage systems of pumping stations instead of traditional centrifugal pumps (for example, of $\mathrm{K}$ type or submersible type ECV) $[4,5,6]$. Jet pumps are really very simple in design, reliable in operation and can pump contaminated liquids. But for all that, they have one significant disadvantage - very low efficiency, incomparable with the efficiency of vane pumps $[7,8,9,10]$. Despite numerous studies of working processes $[11,12,13,14,15]$, improvement of designs and calculation methods $[16,17,18]$, improvement of operating

* Corresponding author: Kan_E1969@email.ru 
modes and regulation $[4,8,19]$, it was not possible to significantly increase the efficiency of water jet pumps. This factor considerably limits the scope of their application. Therefore, there is a rule: water-jet pumps are used for tasks that cannot be performed by a vane pump (self-priming, suppressing cavitation, pumping polluted liquids, etc.). In other cases a vane pump is used. The use of jet pumps at a particular pumping station must be economically justified.

Ejector systems are widely used in hydroelectric power plants (HPPs) as pumps for technical water supply systems [20]. Moreover, in the course of their further operation, it was calculated that the loss of electricity due to the use of water from the upstream is equal to the cost of the variant with the use of paddle pumps and the supply of water from the downstream. And since jet pumps have undeniable advantages in operation (simplicity of design, reliability in operation, lower operating costs, etc.). The choice of jet pumps in this case is justified. Both at hydroelectric power stations and at pumping stations, the source of energy for the operation of jet pumps is water, which in this case is considered as an energy carrier. In hydroelectric power plants, this energy is a natural renewable energy source. Therefore, when comparing the options with the use of jet pumps, the case is considered when this water will pass through a hydraulic unit and will be converted into a useful form of energy (electric). That is, the energy loss when using jet pumps will be equal to the amount of this energy minus the losses in the water pipe and the losses in the equipment (turbine and generator). If the amount of water from the volume intended for idle discharge from the upstream to the downstream is used, then there will be no energy loss at all.

When installing jet pumps at pumping stations, water in the upstream, in the pressure pipelines is also considered as an energy carrier. But in this case, the source of this energy is not natural, but artificial. In fact, this is the energy taken from the power system (taking into account all the losses during transportation and conversion from electrical to mechanical, and then to hydraulic). Taking into account the low efficiency of jet installations, the amount of energy lost can reach significant values and the question of the use of such installations becomes very controversial.

\section{Methods}

We will evaluate the economic feasibility of using jet pumps for pumping drainage water at pumping stations using the example of the Kiziltepa-2 pumping station. The Kiziltepa-2 pumping station is located in the Kizil-Tepa district of Navoi region. The pumping station has been in operation since 1985 and is part of the Kizil-Tepa district administration of the Amu-Bukhara Machine Canal $[21,22,23]$. The design mode of operation of the pumping station is one month (June) with a supply of $38.4 \mathrm{~m}^{3} / \mathrm{s}$ according to the schedule (24 units in operation, 2 units in reserve). In recent years, the operating mode has changed and the NS operates from April to October with a maximum load (up to 23 units) in July-August.

The pumping station is equipped with 26 horizontal pumps of two-way inlet D 6300-80 (24 NDS) driven by synchronous electric motors with a capacity of $2000 \mathrm{~kW}$. The building of the semi-buried pumping station is divided into two blocks by expansion joints. The total length of the building is $91.5 \mathrm{~m}$, width is $30.8 \mathrm{~m}$, total height is $19 \mathrm{~m}$, including the aboveground part- $6 \mathrm{~m}$.

The waterproofing underground part includes two pumping rooms, in which 13 units are installed in a staggered order. The main load-bearing element is a foundation plate with a thickness of $1.2 \mathrm{~m}$ and walls with a thickness of $1.0 \mathrm{~m}$. The pumping rooms are separated by a concrete monolithic gallery of pressure collectors. In each of the pumping rooms, two drainage pits are provided, spaced at different ends of the building. The pit floors serve as entrance and installation platforms. The aboveground part is an industrial building of the frame type with reinforced concrete wall panels and ribbed slabs, consisting of three spans 
united by a common roof. Two spans are located above the pumping rooms, the central span with a width of $6 \mathrm{~m}$ is occupied by a gallery of station collectors, a cable half-floor, a switchgear, a control panel, auxiliary and household rooms. The switchgear is fenced with a metal grid, the rest of the premises-with brickwork.

The drainage rooms are located at the ends of the machine rooms and are separated from the pumping room by a low $(1.0 \mathrm{~m})$ wall. According to the project, the composition of the drainage pumps includes 8 pumps $6 \mathrm{~K}-12$ with an electric motor A2-62-4, $17 \mathrm{~kW}, 1450 \mathrm{rpm}$ and two pumps 8K-18 with an electric motor A2-71-4. $22 \mathrm{~kW}, 1450 \mathrm{rpm}$. The pressure pipes of the drainage pumps are removed to the pre-chamber. The collection and accumulation of drainage water is produced in special drainage wells. Water gets there through drainage ditches located around the perimeter of the pumping room.

In addition to the existing electric pumps K 200-125-330, in 2007, the installation of three water jet pumps in drainage pits No. 1, 2, 3 was completed. The pumps are fed from the pressure pipeline, take the drainage water from the pit and discharge it into the advance chamber. The main arguments in favor of this solution were the following: jet pumps have important advantages for operation because they do not contain moving parts, do not need an electric drive, are easy to maintain and are practically trouble-free. At the moment, there is a question of completely replacing the vane pumps with jet pumps.

To assess the cost-effectiveness of using water jet pumps, it is necessary to take into account all the factors that affect the energy efficiency and reliability of both the individual drainage system and the entire pumping station as a whole.

The positive factors include:

- Operational reliability;

- Convenience, ease of operation.

The only negative factor is the low energy efficiency of water jet pumps. Also, when evaluating the efficiency, it is necessary to take into account the operating modes of the installations.

The task of evaluating and justifying the use of water jet pumps in auxiliary systems of irrigation pumping stations is to determine a criterion that, if possible, could take into account all these main factors.

As such a criterion for solving these problems can serve as a minimum of the discounted costs:

$$
D C_{i}=E_{n} I N V_{i}+O C_{i}=\min
$$

$D C_{i}$ - discounted cost of the i-th option;

$I N V_{i}, O C_{i}$ - capital investments and operational costs for the i-th option;

$E_{N}$ - norm coefficient of economic efficiency of investments.

If $I N V_{w j} \prec I N V_{v p}$ and $O C_{w j} \prec O C_{v p}$, the use of water jet pumps is effective and there is no need for further calculations. If $I N V_{w j} \succ I N V_{v p}$, then the use of water jet pumps requires additional capital investments equal to $I N V_{w j}-I N V_{v p}$. At the same time, there will be annual savings or, conversely, cost overruns.

In general, the annual cost of operating a drainage system consists of the following expenses:

- depreciation charges;

- repair costs;

- cost of electricity;

- maintenance costs for operating personnel;

- other (cost of lubrication, cleaning and labor protection). 


$$
O C=C_{D C h}+C_{R . C}+C_{E C}+C_{M C}+C_{o t h e r}
$$

As a result of the replacement of vane pumps with more reliable and simple water jet pumps, the costs of maintenance of operating personnel (thus taking into account the ease of operation), current and major repairs (taking into account operational reliability) are reduced.

But due to the low energy efficiency of water jet pumps, the amount of electricity consumed (and, accordingly, its cost) will increase slightly.

Then the effect of using water jet pumps will be to reduce the operating costs of the dis. $n$. and consists of the following components:

$$
\Delta O C_{w j}=\Delta C_{R C}-\Delta C_{E C}
$$

$\Delta C_{R C}$ - reduced costs for current and major repairs;

$\Delta C_{E C}$ - increase in energy costs.

It is also necessary to take into account the operating modes of the pumps. If water jet pumps are installed as drainage pumps, there are two possible options for using jet pumps:

- Jet pumps will completely replace all vane pumps and will operate throughout the growing season;

- Jet pumps will be used as emergency pumps, for example, only during power outages, and in the main time, vane pumps will pump drainage water out.

\section{Results and Discussions}

We will conduct a technical and economic analysis of the use of water jet pumps for these cases separately.

Option 1.

The main reason why jet pumps can never completely replace vane pumps is low energy efficiency. Simply put, they have a very low efficiency. Therefore, from these positions, we will compare the existing vane pumps at the pumping station and the proposed replacement of jet pumps. Initial data for comparison: the total flow rate at the outlet of the discharge pipelines is $\mathrm{Q}=100 \ldots 160 \mathrm{l} / \mathrm{s}$, the required pressure $\mathrm{H}=10-15 \mathrm{~m}$.

It is very difficult to determine the cost of electricity during the operation of the water jet pump. We will determine the cost of electricity, taking into account the formula for determining the useful power:

$$
N_{u s e}=\gamma Q H
$$

The value of the useful power required for raising drainage water by 1 pumping unit: $N_{\text {use }}=9.81 * 0.020 * 15=2.94 \mathrm{~kW}$. The efficiency of an installation with jet pumps is in the range of 10-30\% [5], and of a pumping unit with a vane cantilever pump-40-70\% [9,21]. For a system with jet pumps, we assume an average efficiency of $15 \%$. And since water from the pressure line of the main pump is used as the working fluid, it is necessary to take into account the losses in the main pumping unit.

The total power spent on lifting water by the water jet installation will be equal to: 


$$
N_{\text {total }}^{\text {jet }}=\frac{N_{\text {use }}}{\eta_{\text {jet }} * \eta_{m . \text { pump }}}=\frac{2.94}{0.15 * 0.8}=24.5 \mathrm{~kW}
$$

For pumping units with vane pumps, if the average efficiency value is assumed to be $50 \%$, the total power will be equal to:

$$
N_{\text {total }}^{\text {vane }}=\frac{N_{\text {use }}^{\text {vane }}}{\eta}=\frac{2.94}{0.5}=5.88 \mathrm{~kW}
$$

In this case, the "lost power" when using water jet pumps will be:

$$
N_{\text {lost }}=N_{\text {total }}^{\text {jet }}-N_{\text {total }}^{\text {vane }}=24.5-5.88=18.62 k \mathrm{~W}
$$

That is, when using a system with jet pumps, the value of "lost power" (i.e., the energy that will be spent unproductively to overcome various resistances in the system) will be greater than the value of lost energy with existing vane pumps by the amount of $18.62 \mathrm{~kW}$ (for one installation):

This means that in order to ensure the rise of the drainage water flow rate $\mathrm{Q}=160 \mathrm{l} / \mathrm{s}$ with a head $\mathrm{H}=15 \mathrm{~m}$, when replacing with jet pumps, the power of $\Delta N_{\text {lost }}=8 * 18.62=148.96 \mathrm{~kW}$ will be lost.

If the system with water jet pumps will work for the entire growing season, the amount of energy lost will be equal to:

$$
\Delta E_{\text {lost }}=\Delta N_{\text {lost }} * T_{\text {grow }}=148.96 \mathrm{~kW} * 7200 \text { hour }=1072512 \mathrm{~kW} * \text { hour }
$$

At a cost of $\$ 0.04$ per $1 \mathrm{kWh}$, the additional operating costs of replacing the vane pumps with water jet pumps will amount to $\$ 42,900$ per year.

The calculation results are presented in Table 1.

Table 1. Results of calculation of economic indicators of vane and jet pumps

\begin{tabular}{|c|c|c|c|c|c|c|c|}
\hline & \multirow{7}{*}{$\begin{array}{c}\text { Capital } \\
\text { Element }\end{array}$} & \multicolumn{6}{|c|}{ Operational costs, \$ } \\
\cline { 3 - 8 } & $\begin{array}{c}\text { investments } \\
\mathbf{n n y y y y y y}\end{array}$ & $\begin{array}{c}\text { deprecia } \\
\text { tion } \\
\text { charges }\end{array}$ & $\begin{array}{c}\text { repair } \\
\text { costs }\end{array}$ & $\begin{array}{c}\text { cost of } \\
\text { electrici } \\
\text {-ty }\end{array}$ & $\begin{array}{c}\text { Person- } \\
\text { nel }\end{array}$ & other & $\begin{array}{c}\text { total } \\
\text { amount }\end{array}$ \\
\hline $\begin{array}{c}\text { K-type vane } \\
\text { pump }\end{array}$ & 4500 & 450 & 225 & 13547 & 1200 & 142 & 15565 \\
\hline $\begin{array}{c}\text { water jet } \\
\text { pump }\end{array}$ & 3000 & 150 & 75 & 56448 & 600 & - & 57273 \\
\hline
\end{tabular}

The capital investment of the Type K pump includes the cost of the electric motor.

The discounted costs for the variant with vane pumps, taking into account the formula (1):

$$
D C_{v . p}=0.12 * 4500+12178=\$ 12178
$$

Discounted costs for the version with water jet pumps:

$$
D C_{j e t}=0.12 * 3000+43161=\$ 43521
$$


Since $D C_{v . p} \prec \prec D C_{j e t}$, it will be economically profitable to use the variant with vane pumps.

Capital investments in the variant with vane pumps will be slightly more expensive than capex with jet pumps, and the costs on the contrary. The payback period of additional capex:

$$
T=\frac{I N V_{v \cdot p}-I N V_{j e t}}{D C_{j e t}-D C_{v \cdot p}}=\frac{4500-3000}{57273-15565}=\frac{1500}{41708}=0,036 \text { year }
$$

Thus, the calculation of the economic efficiency of jet pumps does not speak in favor of their use. Especially if their work is provided for during the entire growing season. Operating costs (the lion's share of which at pumping stations is electricity costs) for jet pumps (despite the small repair and maintenance costs), taking into account the above calculations, will be higher, and capital investments (cost) jet pumps (custom-made) are comparable to the cost of serial vane pumps.

Option 2.

Jet pumps will be used as emergency pumps, for example, only during power outages.We evaluated reliability parameters by external failures that occurred at the pumping station "Kiziltepa-2" for the period from 2004 to 2011 [24]. The main external failures are power outages [21].

For the analysis of operational reliability according to external failures, the data from the service of operation of the pumping station and the State Inspectorate "Gosvodkhoznadzor" were used [24]. The analysis of external failures showed that for the entire observation period (2004-2011) there were only 22 power outages (an average of 2.75 per year), and their duration (downtime) ranged from 15 minutes (02.08.2008) to $48 \mathrm{~h} 10$ minutes (15.07.2010) with a total duration of 117.35 hours and an average annual duration of 14.67 hours. As the calculation period, we will take the average annual downtime of 14.67 hours. The results are presented in table 2 .

Table 2. Results of calculation of technical and economic indicators of vane pumps operating from diesel generators and jet pumps.

\begin{tabular}{|c|c|c|c|c|c|c|c|c|}
\hline & \multirow{2}{*}{$\begin{array}{c}\text { Capital } \\
\text { investm } \\
\text { ents } \\
\$\end{array}$} & \multicolumn{2}{|c|}{ Operational costs, \$ } \\
\cline { 3 - 9 } & $\begin{array}{c}\text { deprecia } \\
\text { tion } \\
\text { charges }\end{array}$ & $\begin{array}{c}\text { repair } \\
\text { costs }\end{array}$ & $\begin{array}{c}\text { cost of } \\
\text { electrici } \\
\text {-ty }\end{array}$ & $\begin{array}{c}\text { Person- } \\
\text { nel }\end{array}$ & other & $\begin{array}{c}\text { fuel } \\
\text { costs }\end{array}$ & $\begin{array}{c}\text { total } \\
\text { amount }\end{array}$ \\
\hline $\begin{array}{c}\text { K-type } \\
\text { vane } \\
\text { pump }\end{array}$ & 4500 & 0.75 & 0.38 & 28 & 2.0 & 2.0 & 62.1 & 95.23 \\
\hline $\begin{array}{c}\text { water jet } \\
\text { pump }\end{array}$ & 3000 & 0.25 & 0.13 & 115 & 1.0 & - & - & 116.38 \\
\hline
\end{tabular}

Fuel costs when using a diesel generator will be:

$$
C_{\text {fuel }}=b c \mathrm{E}=0.15 * 0.60 * 690=\$ 67.25
$$

b- specific fuel consumption, $\mathrm{kg} /(\mathrm{kWh})$.

c- the cost of diesel fuel, USD $/ \mathrm{kg}$. 
E- electricity consumption $\mathrm{kWh}$.

Thus, the analysis shows that to ensure reliable operation of drainage sediments in the absence of electricity, it is sufficient to have a backup diesel AC power plant for emergency power supply. Such a diesel power plant will provide electricity not only to the drainage pumps, but also to all other consumers at the pumping station: the system of its own needs, fire safety pumps (which must be in a state of constant readiness), and, if necessary, the main pumps with auxiliary systems. Taking into account the insignificant average downtime (only 14.67 hours / year), the use of reliable (but low-efficiency) jet pumps of the drainage system for draining the underground part of the building in the absence of power supply is economically unjustified.

\section{Conclusion}

The conducted analysis and technical and economic calculation shows that the use of water jet pumps in the drainage systems of irrigation pumping stations is economically impractical. Especially if their work is provided for during the entire growing season. Comparison by the method of comparative economic efficiency of water jet and vane pumps shows that it is more preferable to use conventional vane pumps (type $\mathrm{K}, \mathrm{D}$ or submersible type ECV) as drainage pumps. The operating costs for jet pumps (despite the low repair and maintenance costs) are higher. Also capital investments (cost) jet pumps (custom-made) are an order of magnitude higher than the cost of serial vane pumps. Therefore, the use of reliable (but low-efficiency) jet pumps in the drainage system for draining the underground part of the pumping station building is economically unjustified.

\section{References}

1. A.S. Ipanov, M.A Oshivalov, K.S. Galyagin, Yu.A.Selyaninov, M.A.Savin, E.I.Vaxrameev, Mathematical modeling of multiphase hydrojet pump operation, Bulletin PNRPU Mechanical engineering, material science 21, 15-22 (2019)

2. E.K. Spiridonov, S.B. Shkolin, Application of water-air ejector pumps in the systems of deep vacuumization, Vestnik Juzhno-Ural'skogo gosudarstvennogo universiteta serija "Mashinostroenie» 11, 18-28 (2009)

3. E.K. Spiridonov, A.R. Ismagilov, Energy and resource operating water-air jet pumps, Vestnik Juzhno-Ural'skogo gosudarstvennogo universiteta serija "Mashinostroenie» 33, 13-20 (2012)

4. V.A. Khokhlov, A.V Khokhlov, Zh. O. Titova, Regulation of operating modes of jet pumps (Tashkent: "Fan va technology", 118 p, 2011)

5. B.F. Lyamaev, Hydrojet pumps and installations ( Leningrad: Mashinostroenie, 256 p., 1988)

6. N. Ismoilov, N. Nasirova, B. Kholbutaev, Kh. Khusanbayeva, O. Nazarov, Technology of water supply to water inlets of pumping stations, IOP Conf. Series: Materials Science and Engineering 1030, 012156 (2021)

7. O. Glovatsky, R. Ergashev, N. Nasirova, B. Kholbutaev, Kh. Khusanbayeva, Estimation of the forecast of pump ready rate for reclamation systems, IOP Conf. Series: Materials Science and Engineering 1030, 012115 (2021)

8. E. Kan, M. Mukhammadiev, N. Ikramov, Methods of regulating the work of units at irrigation pumping stations, IOP Conference Series: Materials Science and Engineering 869, 042009 (2020) 
9. E. Kan, M. Mukhammadiev, N. Ikramov, The change in the efficiency factor of the pumping unit with a frequency converter, E3S Web of Conferences 97, 05010 (2019)

10. O. Glovatsky, O. Azizov, F. Bekchanov, A. Gazaryan, M. Shomayramov, N. Ismailov, Diagnostic tests of vertical pumps modernized pump stations, IOP Conf. Series: Materials Science and Engineerig 883(1), 012032 ( 2020)

11. V. Cheremushkin, A. Polyakov, Investigation of the influence of geometric parameters of a multi-nozzle jet pump on its energy characteristics, IOP Conf. Series: Materials Science and Engineering 779, 012056 (2020)

12. J.M. Zhu, X.P. Long, S.B. Zhang, X. Lu, Experiment on performance of adjustable jet pump, IOP Conf. Series: Earth and Environmental Science 15, 062063 (2012)

13. H. J. Zhu, B.S. Qiu, Q.K. Jia, X. L.Yang, Simulation Analysis of Hydraulic Jet Pump, J Advanced Material Research 204-210, 293-296 (2011)

14. X. D. Wang, Y.L.Chen, Y.Zhao, Y.Xu, B.Wang, Influence of suction chamber profile on flow field of annular jet pump, IOP Conf. Series: Earth and Environmental Science 304, 032088 (2019)

15. A.A. Saker, H.Z.Hassan, Study of the Different Factors That Influence Jet Pump Performance, Open Journal of Fluid Dynamics 3, 2 (2013)

16. L.L. Cao, B.X. Che, L.J. Hu, D.Z .Wu, Design method of water jet pump towards high cavitation performances, IOP Conf. Series: Materials Science and Engineering 129, 012067 (2016)

17. C. Y. Bityutskikh, E. K. Spiridonov, Research and calculation of hydrodynamics in a jet pump, Bulletin of the South Ural State University series "Mechanical Engineering" 16, 1 (2016)

18. V.A. Barilovich, Yu. A. Smirnov, Improving the calculation of the airlift and jet pump, Scientific and Technical Bulletin of SPbPU, Natural and engineering sciences 23, 38 (2017)

19. E. Kan, M. Mukhammadiev, N. Ikramov, T. Majidov, Full-scale testing of the pump unit with a frequency converter, IOP Conf. Series: Materials Science and Engineering $\mathbf{8 8 3}, 012112(2020)$

20. V.I. Bryzgalov, L.A. Gordon, Hydroelectric Power Stations (Krasnoyarsk: CPI KSTU) 541 p. (2002)

21. N. Ikramov, T. Majidov, E. Kan, A. Mukhammadjonov, Monitoring system for electricity consumption at pumping stations, IOP Conf. Series: Materials Science and Engineering 883, 012101 (2020)

22. N. Ikramov, T. Majidov, E. Kan, D. Akhunov, The height of the pumping unit suction pipe inlet relative to riverbed bottom, IOP Conf. Series: Materials Science and Engineering 1030, 012125 (2021)

23. E. Kan, A. Muratov, M.Yusupov, N. Ikramov, Calculation of water hammer on the pressure pipeline of modernized irrigation pumping station, IOP Conf. Series: Materials Science and Engineering 1030, 012127 (2021)

24. N. Khuzhakulov, Analysis of external failures at the pumping station "Kiziltepa-2", Republican scientific and practical conference on Improving the efficiency, reliability and safety of hydraulic structures, Tashkent (2012) 